\title{
Effect of Lateral Cone Hops and Hurdle Hops Training on the Power of Legs Muscles
}

\author{
Muhammad Sardi Akbar*, Boyke Mulyana, Deris Maulana, Reki Siaga Agustina \\ Sport Education Program, Faculty of Sport Education and Health \\ Universitas Pendidikan Indonesia \\ Bandung, Indonesia \\ *msardiakbar@upi.edu
}

\begin{abstract}
This study aims to determine the effect of lateral cone hops training on the legs muscle power of the karate athletes, the effect of hurdle hops training on the legs muscle power of the karate athletes and the difference in effect between lateral cone hops and hurdle hops training on the legs muscle power of the karate athletes. Subjects in this study were kumite karate athletes. This study used an experimental method with the modified group pre-test post-test design. Data collection tests using the standing broad jump test. Data analysis using calculations the Least Significant Difference (LSD) test the significance level of $\mathbf{a}=\mathbf{0 . 0 5}$ with help by SPSS $\mathbf{1 6 . 0}$ program. It was concluded that, there was an influence of lateral cone hops and hurdle hops training on leg muscle power and there was a difference in influence between lateral cone hops and hurdle hops training where hurdle hops training is better than lateral cone hop training on the legs muscle power of the karate athletes. The trainer should be able to emphasize the hops hurdle training, this is due to better research results than lateral cone hops training.
\end{abstract}

Keywords-lateral cone hops training; hurdle hops training; legs muscle power; karate; plyometri

\section{INTRODUCTION}

Martial arts (e.g., judo, karate, taekwondo, kickboxing) appeal. For example, in France, the Netherlands, Canada, Finland, Australia and Belgium martial arts are on a list of the ten most practiced sports among children and adolescents [13]. Martial arts have also been ranked among the ten most practiced sports in a club context [4].

The popularity of martial arts has helped contribute to a growing interest in martial arts research over the years, which can be illustrated through a number of ways. Firstly, there are indications that in recent years more papers on martial arts are presented at sports scientific congresses. For example, Distaso and his colleagues examined the number of oral and poster presentations on martial arts at the annual conference of the European College of Sport Science (ECSS) and noticed a significant growth between 1999 and 2008 [5].

Karate is a Japanese martial art that involves repeated sequences of strikes and defences. Though of a relative short duration, fights require maximal intensity and a high level of motor and functional abilities including speed, agility, muscle strength, flexibility, coordination and balance [6].
Reynes, suggested that the ability to express high rates of force development and high power outputs are critical performance characteristics central to success in most sporting events and everyone can see that this is totally true in Karate [7].

Power defined in sport, is the product of force and velocity, it can also be defined as the rate of performing work [8]. Maximum power or peak power, is the maximum amount of work a muscle can do per unit time [9]. Candeias, said that you can improve power with training types as [10]: Traditional resistance training exercises, ballistic exercises, plyometric, weightlifting exercises. Power System Inc. explain that plyometric drills Cone Hurdle Set is designed for plyometric training regimens to improve force development and neuromuscular efficiency [11]. The Cone Hurdle Set is a portable training tool designed to improve explosive jumping power and knee lift during plyometric training.

This study aims to determine the effect of lateral cone hops training on the legs muscle power of the karate athletes, the effect of hurdle hops training on the legs muscle power of the karate athletes and the difference in effect between lateral cone hops and hurdle hops training on the legs muscle power of the karate athletes. And we expected that any influence of lateral cone hops and hurdle hops training on leg muscle power and any difference in influence between lateral cone hops and hurdle hops training.

\section{METHOD}

This research using the modified pretest-posttest the same subject design from Shutlleworth [12]. All statistical analysis using SPSS version 20.0 for Windows (SPSS Inc, Chicago, IL, USA). Statistical significance was set at $\alpha=0.05$. Subjects in this study were karate athletes aged 12-17 years in Tri Yudha Sakti Club which consist of 46 people. The instrument test used in this study is a standing broad jump with a validity of 0.963 and reliability of 0.607 .

\section{RESUlT AND DISCUSSION}

Analysis of research data for the variable leg muscle power in lateral cone hops training showed an increase in the mean value. From the description of the data the variable of leg muscle power seen in the treatment group with lateral cone 
hops training experienced an increase in the average value seen from the pre-test and post-test values. The pre-test value has an average value of 192.23 and the average post-test score is 196.69, thus the average value of the treatment group with lateral cone hops training increased by 4.46 with a percentage of $0.08 \%$. From the pre-test and post-test data obtained different data (gain score) that will be analyzed to conduct a research hypothesis test.

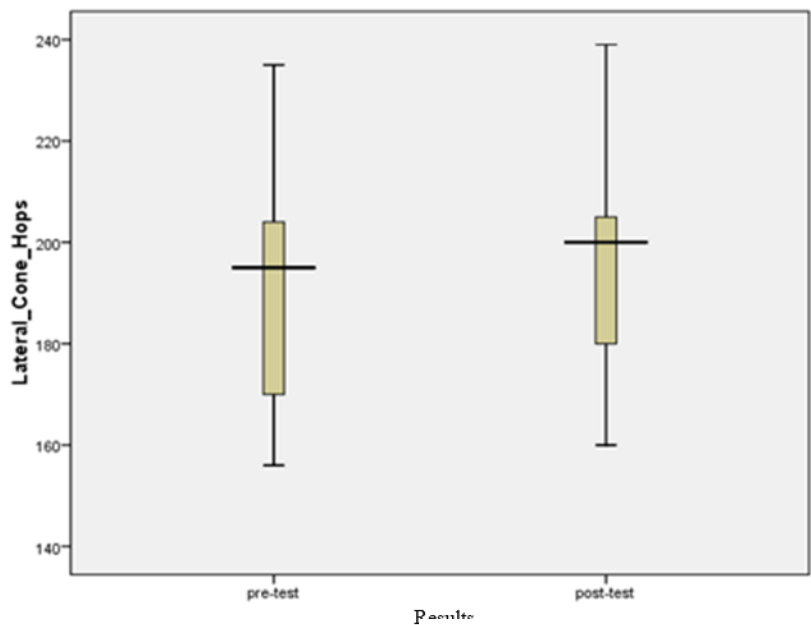

Fig. 1. Histogram data on leg muscle power gain score in the lateral cone hops training group.

Analysis of research data for the variable leg muscle power in hurdle hops training research showed an increase in the mean value. From the description of the data on the power of the leg muscle variable seen in the treatment group with hops hurdle training experienced an increase in the average value seen from the pre-test and post-test values. The pre-test value has an average value of 192.46 and the average post-test value is 200.23 , thus the average value of the treatment group with hops hurdle training increased by 7.77 with a percentage of $0.14 \%$. From the pre-test and post-test data obtained different data (gain score) that will be analyzed to conduct a research hypothesis test.

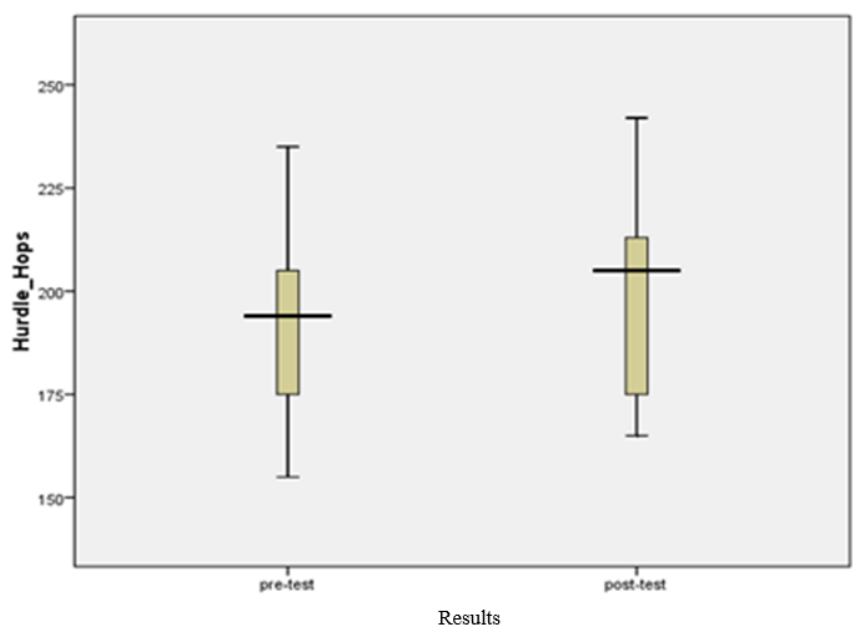

Fig. 2. Histogram data on leg muscle power gain score in the hurdle hops training group.
From the results of the data normality test with the SPSS 20.0 Lilliefors Kolmogorov-Smirnov Test Instrument, the results for lateral cone hops were 0.194 with a significance of 0.193, while for the hurdle group hops 0.136 with a significance of 0.200 . At the significance level $\alpha=0.05$ the significance of the lateral cone hops group and hurdle hops group is greater than $\alpha(\operatorname{sig}>0.05)$ so the data tested is normally distributed.

From the results of the homogeneity test using the Levene test instrument with the help of the SPSS 20.0 program, the value of the levene test was 0.940 and the significance was 0.342 for the variable leg muscle power. The significance value of levene for limb muscle power variable is greater than $\alpha$ (sig> 0.05 ) so the data tested is homogeneous data.

From the results of one-way ANOVA test, the gain score of leg muscle power obtained $F$ value of 4,812 with a significance of 0,038 smaller than $\alpha=0,05$ ( $\mathrm{sig}<0,05)$, so that the hypothesis there is a significant difference in influence of each group received. Because there is a difference in effect between lateral cone hops training and hurdle hops on increasing leg muscle power, then continued with a comparison test with the Least Significant Difference (LSD) test instrument with the help of a 20.0 SPSS computer program at a significance level $\alpha$ $=0.05$. Decision making criteria if the significance value is smaller than $\alpha=0.05$ ( $\operatorname{sig}<0.05)$, then the hypothesis is accepted means that there are significant differences. Whereas if the significance value is greater $\alpha=0.05(\mathrm{sig}>0.05)$, then the hypothesis is rejected which means there is no significant difference.

Least Significant Difference Test (LSD) results obtained a significance value for the lateral cone hops training group of 0.038 , and the hurdle hops training group of 0.038 . The significance value is smaller than $\alpha=0.05$ ( $\operatorname{sig}<0.05)$ which means that there are significant differences in each group. Furthermore, seen from the results of the mean difference in leg muscle power obtained by comparison of the lateral cone hops training group is smaller than the hops hurdle training group of -3.385 and the training group hurdle hops is greater than the lateral cone hops training group of 3.385. From the results of the Mean Difference in the LSD leg muscle test between the lateral cone hops training group and the hops hurdle it can be concluded that the hurdle hops training has a better effect than lateral cone hops training on increasing leg muscle power of 3,385 .

TABLE I. RESUlTS LEAST SigNIFICANT DIFFERENCE TEST (LSD) OF LEG MUSCLE POWER

\begin{tabular}{|c|c|l|l|l|}
\hline $\begin{array}{c}(\mathbf{I}) \\
\text { Group }\end{array}$ & $\begin{array}{c}(\mathbf{J}) \\
\text { Group }\end{array}$ & \multicolumn{1}{|c|}{$\begin{array}{c}\text { Mean Difference } \\
(\mathbf{I}-J)\end{array}$} & Std. Error & Sig. \\
\hline Lateral cone hops & Hurdle hops & -3.385 & 1.543 & .038 \\
\hline Hurdle hops & $\begin{array}{c}\text { Lateral } \\
\text { cone hops }\end{array}$ & 3.385 & 1.543 & .038 \\
\hline
\end{tabular}

\section{CONCLUSIONS}

Based on the results of research and discussion, some conclusions can be drawn, including: (1) There is an effect of lateral cone hops training on leg muscle power in Tri Yudha 
Sakti club karate kumite athletes in Sukasada District in 2015 at $0.08 \%$. (2) There was an effect of hurdle hops training on leg muscle power in Tri Yudha Sakti club karate kumite athletes in Sukasada District at $0.14 \%$. (3) There is a difference in effect between lateral cone hops training and hurdle hops on leg muscle power in the club karate kumite club Tri Yudha Sakti in Sukasada District in. The effect of hurdle hops training is better than lateral cone hops training on leg muscle power in kumite club karate athletes Tri Yudha Sakti in Sukasada District.

The results of this study are limited only to the influence of lateral cone hops training and hurdle hops on leg muscle power in the karate kumite club of Tri Yudha Sakti club in Sukasada District.

\section{REFERENCES}

[1] T. Tammelin, S. Näyhä, A. P. Hills and M. R. Järvelin, "Adolescent participation in sports and adult physical activity," American journal of preventive medicine, vol. 24, no. 1, pp. 22-28, 2003.

[2] Australian Bureau of Statistics, 2009. [Online]. Retrieved from: https://www.abs.gov.au/.
[3] N. Hartstichting, NOC* NSF. Sportparticipatie en evaluatieonderzoek, 2007.

[4] M. Bottenburg, van and J. Heilbron, "De-sportization of fighting contests: the origins and dynamics of no holds barred events and the theory of sportization," International Review for the So- ciology of Sport vol. 41, no. 3, pp. 259-282, 2006.

[5] M. Distaso, A. Maietta, M. Giangrande and R. Villani, "The state of the art of scientific research in combat sports," In: Book of Abstracts of the 14th annual Congress of the European Col- lege of Sport Science, June 2009, Oslo, Norway. pp 599, 2009.

[6] D. Filingeri, A. Bianco, D. Zangla, A. Paoli, and A. Palma, Is karate effective in improving postural control? Archives of Budo, 2012.

[7] E. Reynes and J. Lorant, Karate and aggressiveness among eight-yearold boys. Perceptual and Motor Skills, 2002.

[8] Charles DeFrancesco, Justin Petraglia, Robert Inesta Nick Polizzi, Chris Wade, Course for the Safe and Effective Application of Plyometric Exercise and Jump Training, 2013.

[9] D. Jandacka and F. Vaverka, "A regression model to determine load for maximum power output," Sport Biomech, 2008.

[10] Pedro Candeias, Ten Key Point To Be Explosive In Karate, 2017.

[11] Power System Inc., The Power Behind Performance, 2007.

[12] M. Shutlleworth, Eexperimental Design Final, 2009. 